\title{
G-PROTEIN BINDING FEATURES AND REGULATION OF THE RALGDS FAMILY MEMBER, RGL2
}

Elisa Ferro ${ }^{1}$, David Magrini ${ }^{1}$, Paolo Guazzi ${ }^{1}$, Thomas H. Fischer ${ }^{2}$, Sara Pistolesi $^{3}$, Rebecca Pogni ${ }^{3}$, Gilbert C. White $\mathrm{II}^{4}$, Lorenza Trabalzini ${ }^{*}$

${ }^{1}$ Dipartimento di Biologia Molecolare, and ${ }^{3}$ Dipartimento di Chimica, Università degli Studi di Siena, 53100 Siena, Italy

${ }^{2}$ Department of Pathology and Laboratory Medicine, University of North Carolina at Chapel Hill, Chapel Hill, NC 27599, USA

${ }^{4}$ Blood Research Institute, Medical College of Wisconsin, Milwaukee, WI 53226-3548, USA

Short title: Structure-function analysis of RGL2

Keywords: RalGDS family, Structure-activity analysis, Ras effectors, Exchange factors, Signal transduction

*Corresponding author: Lorenza Trabalzini, trabalzinil@unisi.it

Abbreviations: $\quad$ TMB, 3,3',5,5'-tetramethylbenzidine; $\quad$ Gpp(NH)p, 5'guanylylimidodiphosphate trisodium; GST, glutathione S-transferase; X-gal, 5-Bromo-4chloro-3-indolyl $\beta$-D-galactoside; IPTG, isopropyl-1-thio-b-D-galactopyranoside; Y2H, Yeast Two-Hybrid 


\begin{abstract}
Ral Guanine nucleotide dissociation stimulator-Like 2 (RGL2) is a member of the RalGDS family that we have isolated and characterized as a potential effector for Ras and the Ras analogue Rap1b. The protein shares $89 \%$ sequence identity to its mouse orthologue Rlf. In this study we further characterized the G-protein binding features of RGL2 and also demonstrated that RGL2 has guanine nucleotide exchange activity toward the small GTPase RalA. We found that RGL2/Rlf properties are well conserved between human and mouse species. Both RGL2 and Rlf have a putative PKA phosphorylation site at the C-terminal of the domain that regulate the interaction with small GTPases. We demonstrated that RGL2 is phosphorylated by PKA and phosphorylation reduces the ability of RGL2 to bind H-Ras. As RGL2 and Rlf are unique in the RalGDS family in having a PKA site in the Ras Binding Domain, these results indicate that Ras may distinguish between the different RalGDS family members by their phosphorylation by PKA.
\end{abstract}




\section{INTRODUCTION}

Ras and members of the Ras family are low molecular weight monomeric GTP binding proteins that act as molecular switches by coupling extracellular signals to different cellular responses. Signal transduction through Ras and other members of the Ras family occurs by reversible binding of GTP, while the inactive form of Ras is bound to GDP. Switching between these two states is regulated by positive and negative signals conveyed by GTP exchange factors (GEFs), which catalyze the exchange of GDP for GTP, and GTPaseactivating proteins (GAPs), which hydrolyze GTP. Effector molecules mediate the intracellular effects of Ras family proteins by interacting with the GTP-bound active form. It has become clear in these last two decades that Ras proteins can interact with many effector molecules to activate parallel pathways. The Ser/Thr kinase c-Raf-1, was identified as the first mammalian Ras effector, followed shortly afterwards by Ral Guanine nucleotide Dissociation Stimulators (RalGDSs) and phosphatidylinositol 3-kinase (PI3K) [1].

RalGDS gene was first identified by PCR-based screening using sequences derived from yeast $C D C 25$ gene, and the encoded protein was found to stimulate the dissociation of guanine nucleotides from the Ras family member Ral [2]. RalGDS was also identified independently as a binding partner for Ras in yeast two-hybrid screening [3,4]. Besides this, other proteins homologous to RalGDS, RGL (RalGDS like) [5], Rlf (RalGDS like factor) [6], RGL2 [7], and RGL3 [8,9], have been identified as binding partners for small G-proteins through yeast two-hybrid screening. They act as effectors in that the binding to Ras or Rap is GTP-dependent, but they also have a sequence that suggests they can act as exchange factors. Thus, they have a structure that suggests they might mediate cross-talk or amplification between $\mathrm{G}$ proteins, binding to one $\mathrm{G}$ protein and activating another.

All the RalGDS family proteins contain a central CDC25 homology domain, a N-terminal Ras Exchange Motif (REM) [10], and a C-terminal Ras/Rap Binding Domain (RBD) (Fig.1A).

The Ras binding abilities of RalGDS family proteins depend on their C-terminal region which is highly conserved in the family (Fig.1B). The minimal Ras Binding Domain (RBD) of RalGDS, RGL and Rlf has been identified by N- and C- terminal deletion truncation [6,11-13], and the three-dimensional structure determined by NMR spectroscopy and/or Xray crystallography [14-16]. Similarities in the hydrophobicity profiles and three-dimensional folding between the Ras-binding domains of RalGDS family members and the Ras effector Raf have been noted, although the sequence identity is very low [17]. As with Raf-RBD, the 
RBD domains of RalGDS, RGL and Rlf assume an ubiquitin-like conformation characterized by $\beta \beta \alpha \beta \beta \alpha \beta$-type tertiary structure [14-16,18].

The CDC25 homology domain is downstream to the REM motif (see Fig.1A). CDC25 is a GEF for Ras in yeast cells, where it regulates the conversion of the inactive GDP-bound form of Ras to the active GTP-bound form [19]. The catalytic domain is a region of about 250 residues. Five structurally conserved regions (scr1-5) were noted in this domain by sequence alignment of multiple yeast and mammalian GEFs. Although the core catalytic domain of CDC25 is able to function as a GEF in vitro, a larger region of about 450 residues is required in vivo. This larger sequence encompasses an approximately 50 residue $\mathrm{N}$-terminal homology region that has been variably described as the REM, CNC (Conserved Non Catalytic), LTE1 homology region (after the yeast GEF, LTE1) or scr0 (being $\mathrm{N}$ terminal of scr1) in the literature; this region is required for maintaining the conformation of the catalytic CDC25 domain [10]. Many proteins from different organisms have a CDC25 homologous domain that has been characterized as a GEF for different proteins of Ras family [10]. The CDC25 homology domain of the RalGDS family proteins, RalGDS, RGL3, Rlf, acts as an exchange factor for Ral, a member of the Ras family $[2,8,20]$ but a more detailed analysis of the GEF activity spectrum is lacking.

RGL2 was first identified through a yeast two-hybrid screen for Rap1 binding proteins [7]. The full sequence of the $R G L 2$ gene, encoding 777 aminoacids, was subsequently established by sequencing of a centromeric region of human chromosome 6 [21]. RGL2 shares 89\% amino acid sequence identity in its entire protein sequence to its mouse orthologue Rlf and $22-25 \%$ amino acid sequence identity to the other members of the family. The highest sequence homology between RGL2 and the other members of the family is in the three functional domains, REM, CDC25 and RBD.

A C-terminal 158 amino acid fragment of RGL2 interacts specifically with Ras family proteins that share identical effector domain sequences with Rap1 (H-Ras, R-Ras, Tc21). The interaction between RGL2 C-158 is GTP-dependent and requires an intact Rap1 and H-Ras effector domain, thus indicating that RGL2 might be a potential effector for Ras proteins [7]. Furthermore, studies on NIH3T3 and A10 cells clearly indicated an involvement of RGL2 in cellular processes regulated by Rap1 and Ras [7,22].

In the present study, we further characterized the G-protein binding features of RGL2 by analysing the properties of its putative functional domains. In particular, we assayed the ability of the N-terminal domain of RGL2 to function as exchange factor towards different proteins of the Ras family. We determined the minimal binding domain of RGL2 for Ras and 
Rap $1 b$ and the critical sequences for interaction; finally we demonstrated that the Ras Binding Domain of RGL2 is phosphorylated by Protein Kinase A and that phosphorylation affects the ability of RGL2 to bind both H-Ras and Rap1b.

\section{EXPERIMENTAL}

Two-hybrid analysis of RGL2 interaction - The different mutants of RGL2 were made by PCR using RGL2 (647-736) [23] as a template and then fused in-frame with the GAL4 activation domain in the Y2H pGAD424 vector (Clontech Laboratories Inc., Mountain View, CA) as EcoRI/BamHI inserts. All constructs were verified by sequencing. Expression of GAL4AD fusion proteins in yeast cells was verified by Western blot analysis with anti-GAL4 AD monoclonal antibody.

pGBT9 constructs carrying cDNAs encoding wild type and G12V, S17N, T35A and E37G mutant Rap1b, H-Ras(G12V), wild type RalA, RhoA and Rac1 were prepared in a previous work [7]. The constructs pGBT9-wild type H-Ras and pGBT9-H-Ras(T35A) were kindly provided by Linda van Aelst and Michael Wigler (Cold Spring Harbor Laboratories, Cold Spring Harbor, NY).

The interaction of different fragments of RGL2 with native and mutated forms of H-Ras and Raplb was assayed by a two hybrid assay as already described [7].

Expression and purification of GST-fusion proteins - The constructs pGEX-RalA and pGEX-HRas were provided by Douglas Andres (University of Kentucky, College of Medicine, Kentucky, USA).

RGL2(647-736), RGL2(647-706), RGL2(677-736), RGL2(262-777), RGL2(681-777), RGL2(544777), Rap1b, RhoA and Rac1 coding sequences were fused into the pGEX-4T-3 vector (Amersham Pharmacia Biotech, UK Ldt.) as BamHI-EcoRI inserts. RGL2(544-777)(S737A) was prepared by recombinant PCR using the wild type fragment as a template and cloned as above. RGL2(1-518) and RGL2(83-518) were amplified by PCR and then ligated into the pGEX-4T-1 vector via EcoRI site. The different fragments of RGL2 were expressed and purified as GST fusion proteins by using the GST Gene Fusion System (Amersham Pharmacia Biotech ), as already described [23]. GST fusion proteins were finally analyzed by Western blotting with an anti-GST antibody (Amersham Pharmacia). The amount of expressed proteins was determined by using the Bradford method [24].

Expression and purification of N-terminal His-tagged proteins - H-Ras(G12V) and Rap1b(G12V) cDNAs were ligated into the pET28a vector (Novagen, Madison, WI, USA) as BamHI-SalI inserts. The constructs were used to transform BL21(DE3) cells (Novagen). 
Transformed cells were then grown overnight at $37^{\circ} \mathrm{C}$ in $2 x$ YTG medium containing kanamycin (30 $\mu \mathrm{g} / \mathrm{ml})$. The cell suspension was then diluted 1:50 with fresh 2x YTG-kan medium and incubated at $37^{\circ} \mathrm{C}$ to an adsorbance of 0.6-0.8 (600 nm). After incubation, IPTG $(100 \mathrm{mM})$ was added to a final concentration of $1 \mathrm{mM}$ and the cells were grown for 6 hours at $30^{\circ} \mathrm{C}$. Cells were then collected by centrifugation at $5000 \mathrm{xg}$ for $20 \mathrm{~min}$ at $4^{\circ} \mathrm{C}$, and the resulting pellet was resuspended in Lysis Buffer (50 mM NaH $2 \mathrm{PO}_{4}, 300 \mathrm{mM} \mathrm{NaCl}, 10 \mathrm{mM}$ Imidazole, $\mathrm{pH} 8.0,4 \mathrm{ml} / \mathrm{g}$ of pellet) containing protease inhibitors $(28 \mu \mathrm{M}$ E64, 1mM PMSF, 1mM AEBSF, 10 $\mu \mathrm{M}$ Pepstatine A, 10 $\mu \mathrm{M}$ Leupeptin, 1mM Benzamidine). After incubation with Lysozyme $(100 \mu \mathrm{g} / \mathrm{ml})$ for $30 \mathrm{~min}$ in ice, cells were frozen at $-20^{\circ} \mathrm{C}$, thawed and finally lysed by sonication. The cell lysate was centrifuged at $4^{\circ} \mathrm{C}$ for 30 min at $10000 \mathrm{x}$; ; the supernatant was mixed with Ni-NTA agarose according to the manufacturer's instructions (Qiagen S.p.A., Milano, Italy), gently shaken at $4{ }^{\circ} \mathrm{C}$ for $60 \mathrm{~min}$ and then loaded into a column. After two washing steps with buffer containing $\mathrm{NaH}_{2} \mathrm{PO}_{4}(50 \mathrm{mM}), \mathrm{NaCl}(300 \mathrm{mM})$, Imidazole $(20 \mathrm{mM}), \mathrm{pH} 8.0$, proteins were eluted 4 times with $0.5 \mathrm{ml}$ of elution buffer $(50 \mathrm{mM}$ $\mathrm{NaH}_{2} \mathrm{PO}_{4}, 300 \mathrm{mM} \mathrm{NaCl}, 250 \mathrm{mM}$ Imidazole, $\mathrm{pH}$ 8.0). Purified proteins were analyzed as above. The immunodetection of N-terminal His-tagged proteins was performed by using RGS-His HRP conjugate antibody (Qiagen S.p.A., Milano, Italy).

ELISA format binding assay - The in vitro interaction of different fragments of RGL2 with Ras proteins has been studied using a method described by Ghosh et al. [25]. Briefly, 50 pmoles of purified His-tagged H-Ras $(\mathrm{G} 12 \mathrm{~V})$ or His-tagged Raplb(G12V) in coating buffer $\left(10 \mathrm{mM} \mathrm{Na}_{2} \mathrm{CO}_{3}\right.$, $30 \mathrm{mM} \mathrm{NaHCO}_{3}, \mathrm{pH}$ 9.6) were loaded onto the wells of a 96-well titer plate and allowed to bind overnight at $4^{\circ} \mathrm{C}$ in the presence of $\mathrm{Gpp}(\mathrm{NH}) \mathrm{p}(50 \mathrm{mM})$ (Sigma). After a 2 hour blocking at $37^{\circ} \mathrm{C}$ with BSA $(0.1 \%)$ in PBS buffer, GST-fusion proteins (test proteins) in PBS-BSA $(0.1 \%)$ were added and incubated at $37^{\circ} \mathrm{C}$ for 1 hour. The plate was washed three times in PBS-Tween $20(0.1 \%)$ and incubated with anti-GST antibody (1:3000 dilution) (Amersham Parmacia) for 1 hour at room temperature. After three washings in PBS-Tween $20(0.1 \%)$ the plate was incubated with anti-goat IgG-peroxidase conjugate (Sigma, 1:25000 dilution) for 1 hour at $37^{\circ} \mathrm{C}$. Every single step of the assay was performed in the presence of $50 \mathrm{mM} \mathrm{Gpp(NH)p.} \mathrm{TMB} \mathrm{was} \mathrm{finally} \mathrm{used} \mathrm{as} \mathrm{chromogen} \mathrm{and}$ the reaction blocked with $\mathrm{H}_{2} \mathrm{SO}_{4}(0.5 \mathrm{M})$. The resulting absorbances were detected at $450 \mathrm{~nm}$ on an ELISA plate reader (Molecular Devices, VERSAmax tunable microplate reader).

In vitro guanine nucleotide exchange reactions - GDP dissociation from several Ras family members in the presence or in the absence of RGL2(1-518) or RGL2(83-518) was measured using a method described by Shao et al. [8]. Briefly, 0.1 nmoles of the different Ras proteins fused to GST 
were incubated with 0.1 nmoles of $\left[{ }^{3} \mathrm{H}\right]$ GDP (Amersham Pharmacia) in $50 \mu$ of loading buffer containing Tris- $\mathrm{HCl}$ (20 mM, pH 7.5), $\mathrm{NaCl}$ (100 mM), EDTA (1 mM), $\mathrm{MgCl}_{2}$ (0.919 mM), DTT (1 $\mathrm{mM})$, and BSA $(1 \mu \mathrm{g} / \mu \mathrm{l})$ at $30^{\circ} \mathrm{C}$ for $30 \mathrm{~min}$ to allow $\left[{ }^{3} \mathrm{H}\right] \mathrm{GDP}$ loading. $\mathrm{MgCl}_{2}$ was then added to the incubation mixture to adjust the final $\mathrm{MgCl}_{2}$ concentration to $10 \mathrm{mM}$. Unlabeled GDP was added to the reaction buffer to a final concentration of $1 \mathrm{mM}$ to initiate $\left[{ }^{3} \mathrm{H}\right] \mathrm{GDP}$ dissociation in the presence or in the absence of recombinant GST-RGL2(1-518) or GST-RGL2(83-518) (5 $\mu \mathrm{M})$. The reaction was carried out at $20^{\circ} \mathrm{C}$. At the indicated times after the addition of unlabeled GDP, reaction was stopped by adding to each sample $2 \mathrm{ml}$ of ice-cold washing buffer $(20 \mathrm{mM}$ Tris- $\mathrm{HCl}, 100 \mathrm{mM} \mathrm{NaCl}$, $10 \mathrm{mM} \mathrm{MgCl} 2,1 \mathrm{mM}$ DTT, $\mathrm{pH}$ 7.5). The samples were then filtered on nitrocellulose membrane $(0.45 \mu \mathrm{m})$, washed and counted for radioactivity.

In vitro phosphorylation assay - Phosphorylation of purified GST, GST-RGL2(262-777), GSTRGL2(681-777), GST-RGL2(544-777) and its mutant S737A was obtained by incubating 20 pmol of each protein with the PKA catalytic subunit (0.2 U) (Sigma, St.Louis, MO, USA) for 30 min at $30^{\circ} \mathrm{C}$ in a $0.01 \mathrm{ml}$ reaction mixture containing Tris- $\mathrm{HCl}(20 \mathrm{mM}, \mathrm{pH} 7.5)$, EGTA $(1 \mathrm{mM}), \mathrm{MgCl}_{2}(5 \mathrm{mM})$ and $\gamma-\left[{ }^{32} \mathrm{P}\right] \mathrm{ATP}(0.002 \mathrm{mCi})$ (Amersham Pharmacia). The reaction was stopped by adding the same volume of reduced sample buffer and boiling for three minutes. The entire incubation mixtures were analyzed by SDS-PAGE [26] followed by autoradiography.

For interaction studies, phosphorylated GST-RGL2(544-777) was obtained by incubating 10 pmol of protein with the PKA catalytic subunit $(5 \mathrm{U})$ for 1 hour at $30^{\circ} \mathrm{C}$ in a $0.01 \mathrm{ml}$ reaction mixture containing ATP (0.1mM), Tris-HCl (20mM, pH 7.5), EGTA (1mM), and $\mathrm{MgCl}_{2}$ (5 mM). Incubation mixtures with GST or RGL2(544-777) without the PKA catalytic subunit were prepared as control. After phosphorylation, aliquots of incubation mixtures containing about $2 \mu \mathrm{g}$ of phosphorylated or unphosphorylated GST-RGL2(544-777) were analyzed on a 16\% polyacrylamide gel by SDS-PAGE. Phosphorylated protein was stained with Pro-Q Diamond phosphoprotein gel stain (Life Technology, Carlsbad, CA, USA) and visualized by using a Typhoon 9400 apparatus (Amersham Biosciences).

Phosphorylated and unphosphorylated RGL2(544-777) were used in the ELISA format assay already described to compare their ability to bind H-Ras(G12V) and Rap1b(G12V).

Phosphorylation of RGL2 in mammalian cells - Full length wild-type RGL2 (RGL2wt) and RGL2(S737A) coding sequences were ligated in pEGFPC2 vector (Clontech) .

Human embryonic kidney cells (HEK293) were maintained in Dulbecco's modified Eagle's medium (DMEM) with $10 \%$ foetal bovine serum (FBS) and $1 \%$ penicillin/streptomycin at $37^{\circ} \mathrm{C}$ in $5 \% \mathrm{CO}_{2}$. Cells were transfected by the calcium phosphate method with pEGFPC2-RGL2wt or pEGFPC2- 
RGL2S737A or empty vector and allowed to grow for 48 hours. Cells were serum-starved for 4 hours and then incubated for $30 \mathrm{~min}$ in the presence or in the absence of $20 \mu \mathrm{M}$ forskolin. Following drug treatment cells were washed twice with PBS and harvested in $0,5 \mathrm{ml}$ of lysis buffer $(10 \% \mathrm{v} / \mathrm{v}$ glycerol, 1\% v/v NP40, 50mM Tris. $\mathrm{HCl} \mathrm{pH} 7.4,200 \mathrm{mM} \mathrm{NaCl}, 2,5 \mathrm{mM} \mathrm{MgCl}$ ) containing protease inhibitors (1mM PMSF, 1mM AEBSF, 10 $\mathrm{mM}$ Pepstatin A, 10 $\mu \mathrm{M}$ Leupeptin, $1 \mathrm{mM}$ Benzamidine) and phosphatase inhibitors $\left(1 \mathrm{mM} \mathrm{Na} \mathrm{VO}_{4}, 10 \mathrm{mM} \mathrm{NaF}\right)$. The cell lysates were then centrifuged 10 min at $15000 \mathrm{xg} 4^{\circ} \mathrm{C}$ and supernatants were transferred to a new centrifuge tube. Protein concentrations were determined by the Bradford assay. GFP-fusion proteins were immunoprecipitated from cell protein extract with anti-GFP antibody (Abcam, Cambridge UK), and then analyzed by SDS-PAGE followed by ProQ Diamond gel staining. The same gel was then washed twice with $\mathrm{H}_{2} \mathrm{O}$ and stained with Coomassie Brilliant Blue. A second gel was run as a control with the same amount of proteins and analyzed by Western blotting with anti-GFP.

\section{RESULTS AND DISCUSSION}

Structure-function analysis of RGL2-RBD - We have previously shown that the smallest RGL2 region interacting with Ras and Rap1b is a C-terminal 151 aminoacids fragment (RGL2(627-777)) [7]. This fragment contains a 90 amino acids region (647-736) that presents a very high homology with the RBDs of RalGDS family members (Fig. 1B). On the basis of this evidence, we speculated that RGL2(647-736) might be the domain of RGL2 directly involved in the interaction with Ras proteins. To test this hypothesis, we produced RGL2 deletion mutants encoding either RGL2(647736) fragment or the RGL2(647-706) and RGL2(677-736) shorter fragments lacking C- and Nterminal 30 aa residues, respectively (Fig. 2A), and examined the binding of these fragments to $\mathrm{H}$ Ras and Rap1b using both a two-hybrid and an in vitro assay. As shown in Fig.2B, the RGL2(647736) fragment interacted in a two-hybrid assay with wild type H-Ras and Raplb and dominant positive mutants of H-Ras and Raplb with defective GTPase activity (G12V). Wild type and constitutively activated (G12V) mutants of Rap1b and H-Ras interacted with very similar affinity in the semiquantitative $\beta$-galactosidase filter assay (fig $2 \mathrm{~B}$ ). The lack of an endogenous yeast GAP activity for Ras and Rap [27] may explain why activating mutations did not result in higher interaction with the RGL2 fragment. Rap $1 b(\mathrm{~S} 17 \mathrm{~N})$, a dominant negative mutant with higher affinity for GDP than GTP, showed no detectable interaction with RGL2(647-736), suggesting that RGL2(647-736) mutant exhibits preferential binding to the active GTP-bound form of Rap1b. On the 
other hand, no detectable interaction was observed between the RGL2(647-706) and RGL2(677-736) fragments and H-Ras or Rap1b in the two-hybrid assay conditions (Fig.2B).

To further analyse the binding of RGL2 mutants to Ras/Rap, GST-fusion proteins containing the different fragments of RGL2 were used in an ELISA based assay [25] together with N-terminal Histagged H-Ras(G12V). As shown in Fig.2C, RGL2(647-736) was able to bind GTP-H-Ras(G12V), confirming the yeast two-hybrid results. Deletion of the highly conserved N-terminal 30 amino acids of RGL2(647-736) abrogated the binding to activated H-Ras; deletion of the C-terminal 30 amino acids reduced but did not abrogate the ability of RGL2 to associate with H-Ras in vitro. The same RGL2 mutant was unable to interact with Ras/Rap in the in vivo two hybrid assay (see Fig. 2B), suggesting that this shorter fragment, even though it is stabily expressed in yeast cells (as verified by Western blot analysis of GAL4AD fusion proteins, data not shown), would have difficulty in folding properly, thus affecting the ability to bind Ras. This evidence indicates a structural relevance of the C-terminal portion of the RGL2(647-736) domain.

These results indicate that the fragment RGL2(647-736) is the minimal binding domain of RGL2 for Ras and Rap1b (RGL2-RBD). Our findings are in agreement with data concerning the RBDs of the other RalGDS family members [6,11-13] and are further supported by a three-dimensional model of the RGL2(647-736) region [23] showing that this portion may fold in a canonical RBD $\beta \beta \alpha \beta \beta \alpha \beta$ type tertiary structure (Fig.3A).

As shown in Fig.1B, RGL2-RBD contains many conserved residues. On the basis of the RGL2 3D model and taking into account what had already been demonstrated for other members of the family $[13,18,28]$, we generated eight different mutants of RGL2(647-736) and assayed their interaction with Ras/Rap by two hybrid assay. Among conserved residues (grey residues in Fig.1B), we chose charged, fully solvent-exposed residues that appeared likely to interact with Ras proteins.

As shown in Table 1, the interaction of RGL2-RBD with wild type Raplb and H-Ras was abrogated by substitution of Arg653, Lys666 and Lys686 with Ala. Mutation of residues adjacent to these critical residues (Y665A and N687A) produced RGL2 fragments still able to interact with Ras proteins but with lower affinity in the semiquantitative $\beta$-galactosidase filter assay. The effects of the various mutations on binding to Rap $1 b$ were similar to the effects on binding to H-Ras. Substitution of Arg682 with Ala did not have any effect on the binding to either molecule. Substitution of Asp690 with Ala did not abrogate the interaction with Rap1b and H-Ras; the binding to H-Ras appeared to be stronger than the binding to Rap1b. The RGL2-RBD(Y719A) mutant still interacted with H-Ras and Rap1b. 
It has been observed previously that Lys687 in Rlf, corresponding to Lys686 in RGL2, is essential for Ras association [13]; here we demonstrated that Arg653 and Lys666, in addition to Lys686 are critical residues for the interaction of RGL2 with its target G proteins. On the basis of the predicted three-dimensional structure of the RGL2-RBD, the three residues are exposed at the same side of the RGL2 tertiary fold and located in the $\beta 1$ strand, $\beta 2$ strand and $\alpha 1$ helix, respectively (see Fig.3A). The reciprocal position of the three critical residues and their location in the tertiary fold of RGL2RBD, as well as the evidence that their absence (in the RGL2(677-736)) completely abrogated both in vivo and in vitro interaction, strongly support their participation in the binding event. This is all consistent with a requirement for positively charged residues on $\beta 1, \beta 2$ and $\alpha 1$, which form a structural epitope required for productive complex formation for Ras/Rap binding proteins [29]. As with Lys686, Arg682 is a positively charged, fully solvent-exposed residue of the $\alpha 1$ helix, but its substitution with Ala did not affect the interaction of RGL2 with Ras and Rap, indicating that Arg682 does not participate in the binding. Indeed, in our 3D model (Fig. 3A) Arg682 is not exposed on the same side compared to Lys686, Lys666 and Arg653. To better explain our experimental data, we generated an homology model of the RGL2-RBD/Ras complex taking the crystallographic structure of the RalGDS-RBD/Ras complex as reference (Fig. 3B). In the model it is evident that Arg682 is located far from the RGL2-90 active site (depicted in green) and in particular far from any residue of Ras. Thus, mutations at this site do not affect binding because of the lack of any type of interaction. These findings indicate that, like the other RalGDS family members, the residues in the RGL2-RBD that mediate binding to Ras proteins are located at sites that correspond to those that mediate the interaction of Raf with Ras (in the Raf-binding domain) [18,28,30]. The correlation exists despite the fact that the RGL2- and Raf-Ras binding domains lack extensive aminoacid sequence similarity.

In contrast, the substitution of the negatively charged Asp690 with Ala (RGL2(D690A)) increased the binding affinity toward H-Ras compared to native RGL2. A previous study of the interaction of Ras with the RBD domain of RalGDS family members showed that the negative charge of Asp820 in RalGDS-RBD exerts a repulsion effect with Glu31 residue in Ras [31]; this putative electrostatic repulsion is conserved in the Ras-RGL interaction and involves the same residue in Ras and Glu689 in RGL-RBD, corresponding to Asp820 in RalGDS [28]. Here, we demonstrate that this effect is also conserved in the Ras-RGL2 interaction between H-Ras Glu31 and RGL2 Asp690. As Rap1b has a Lys in position 31 instead of a Glu, it can be expected that D690 of RGL2 and K31 of Rap would have a salt-bridge interaction and then the D690 mutation would cause decreased binding to Rap. However, this hypothesis is not supported by our experimental data, as the interaction of RGL2 with Rap $1 b$ was not affected by substitution of Asp690 with Ala (see table 1). Thus, it is possible that the 
D690A mutation, although potentially able to affect a putative salt-bridge interaction, does not interfere sufficiently with the strength of the RGL2-RBD/Rap1b interaction to cause decreased binding.

Substitution of Tyr719 with Ala had no effect on the interaction between RGL2-RBD and Ras/Rap1b, indicating that Tyr 719 does not directly participate in the interaction between RGL2 and Rap or Ras. Tyr 719 is located in the C-terminal region of the RGL2-RBD, a region with many conserved residues and important for the interaction because its deletion abrogated the binding to both Ras and Rap in vivo (Fig. 2B). Previous studies of the three-dimensional structure of RalGDS, RGL and Rlf [14-16] demonstrated that the RBD C-terminal region strongly contributes to the domain folding due to the hydrophobic interactions between its residues. Sequence alignment of the RGL2 RBD with that of RalGDS showed that 14 of the 15 residues that form the hydrophobic core in RalGDS are conserved in RGL2 (Ile652, Val654, Ile668, Val670, Ala676, Va1679, Ile680, Leu699, Ile711, Val717, Phe718, Ala720, Phe728 and Leu730, see Fig 1B). Most of these residues belong to the consensus hydrophobic residues in ubiquitin and all RA (Ras Associating) domain sequences $[17,18,32]$. The almost total homology between RGL2 and RalGDS that we found at the level of residues that form the hydrophobic core, when considered with our experimental results, support the hypothesis that the $\mathrm{C}$-terminal region plays a role in stabilizing the active binding conformation of RGL2-RBD. On the basis of our 3D model of RGL2, the C-terminus does not directly participate in the interaction, but its presence may be a determinant for the proper folding of the $\beta 1, \beta 2$ and $\alpha 1$ domains that contain critical residues for the interactions.

Previous work showed that the Ras effector domain (spanning between residue 30 and residue 40) was essential for its interaction with Raf-1 [33,34]; Rap1b has a 50\% sequence homology with Ras, and the sequence of its effector domain is identical to that of the Ras effector domain. To further examine the interaction between RGL2-RBD and H-Ras and Rap1b, we studied several effector domain mutants. As shown in Table 2, wild type RGL2-RBD (WT) interacted with wild type H-Ras and Rap1b but not with the two effector domain mutants H-Ras(T35A) and Rap1b(T35A). A second effector domain mutation in Rap1b, E37G, did not abrogate the interaction with RGL2-RBD. RGL2RBD(K686A) did not interact with H-Ras and Rap1b mutants. The interaction of RGL2-RBD with Rap1b(E37G) appeared to be stronger when Asp690 is substituted by Ala. Based on the crystal structure of the Ras/RalGDS-RBD complex, Thr35 of Ras is involved in the interaction with RalGDS-RBD [28]. We showed that Thr35 in the effector domains of H-Ras and Rap1b plays a role in the binding with RGL2. The second effector domain mutation in Rap1b (E37G) did not affect the interaction of the protein with RGL2-RBD. This later result is consistent with findings that these 
mutations define different functions of the effector loop. Glu37 has been demonstrated to be important for the interaction of Rap with Raf [35]. The increase of binding affinity between Rap1b(E37G) and RGL2(D690A) in the semiquantitative $\beta$-galactosidase assay may indicate the existence of a repulsive effect in native proteins between Glu37 (in Rap1b) and Asp690 (in RGL2) that is abrogated by substitution with two small and apolar residues (Gly in Rap1b and Ala in RGL2).

Analysis of GEF activity of RGL2 - RGL2 possesses a N-terminal domain which has significant homology with CDC25, an exchange factor for Ras. It has been previously shown that Rlf functions as an exchange factor both for RalA and RalB, but not for H-Ras [20]. In addition, Shao et al. demonstrated that in RGL3 the Ral-GEF activity is mediated by a N-terminal 518 aminoacids region of the protein [8]. To determine the GEF activity of RGL2 toward Ras, Rap and Ral proteins, we employed an in vitro nucleotide exchange assay. Two members of the Rho family were also used in the assay to evaluate if RGL2 could be involved in crosstalk between Ras and Rho proteins [36]. Based on the Shao study, we first generated a 518 aminoacid N-terminal fragment of RGL2, RGL2(1-518), containing the CDC25 homology domain, but not the RBD domain, and evaluated its GEF activity for H-Ras, RalA, Rap1b, Rac1 and RhoA. As shown in Fig.4 A, RGL2(1-518) was able to stimulate the dissociation of $\left[{ }^{3} \mathrm{H}\right] \mathrm{GDP}$ from RalA but not from the other proteins used in the assay. Sequence alignment of RGL2(1-518) with CDC25 (Fig.5) showed that the region of RGL2 homologous to CDC25 spans between 92 and 512 residues. In order to see if this region was sufficient for the GEF activity of RGL2, we produced a deletion mutant of RGL2(1-518), RGL2(83518), containing the CDC25 homology region flanked by very short non homologous fragments. As showed in Fig.4B, the 83-518 fragment of RGL2 maintained the GEF activity toward RalA. Comparison to CDC25 permitted us to define in this fragment two regions of RGL2, 92-140 and 243512 , corresponding to the REM motif and to the core catalytic domain of CDC25, respectively (see Fig. 5). Both regions are required for exchange factors activity. Based on the crystal structure of Sos1, the REM motif itself does not have catalytic activity, but plays a key role in stabilizing the large helical hairpin structure that pries open the GTP-binding pocket [10].

Phosphorylation analysis - It has been reported that RalGDS is phosphorylated in vitro and in intact cells by PKA on serine residues [2], but this phosphorylation has been reported to affect neither its interaction with Ras nor its GDS activity for Ralp24 [37]. RGL can be phosphorylated by PKA in vitro, but its phosphorylation does not affect its binding to Ras p21 and Rap1 [38]. Thus, the physiological significance of the phosphorylation of the two RalGDS proteins by PKA still remains 
to be clarified. On the other hand, determining if RalGDS proteins contain regulatory regions and how they function in vivo might provide insight into signaling through this family of proteins. Analysis of the RGL2 primary structure by using the software NetPhos 2.0 (http://www.cbs.dtu.dk/services/NetPhos/) revealed a number of Ser residues as putative sites for phosphorylation. Among those with a higher score to be phosphorylated, only Ser737, corresponding to Ser738 in Rlf, constituted a potential PKA site. This sequence is located at the end of the RBD domain; this location is unique for RGL2 and its orthologue Rlf as the other RalGDS proteins do not have PKA phosphorylation sites in the same region. This so far appears to be the only significant difference between RGL2/Rlf and the other members of the RalGDS family and could indicate a peculiar mechanism of regulation of RGL2 by PKA.

In order to determine if RGL2-RBD is a PKA substrate we mixed the catalytic subunit of PKA, the GST-deletion mutant fusion proteins RGL2(262-777) or RGL2(681-777) and [ $\gamma-32$ P]ATP. Samples were electrophoresed and subjected to autoradiography. Fig.6A shows that the RGL2(681-777) mutant, containing the Ras Binding Domain, as well as the longer RGL2(262-777) mutant, were both PKA substrates. The stoichiometry of phosphate transfer was approximatively one to one as determined from the specific radioactivity of radiolabeled bands. To prove that Ser737 is a phosphorylation site by PKA, the C-terminal fragment RGL2(544-777) was mutated at Ser737 and then phosphorylated with the catalytic subunit of PKA. As shown in Fig.6B, only the native RGL2(544-777) but not the mutant lacking Ser737 is a substrate for PKA.

To examine the effect of the phosphorylation of RGL2 by PKA on its ability to bind H-Ras and Rap1b, RGL2(544-777) was incubated with the catalytic subunit of PKA in the presence of ATP. Phosphorylation was verified by SDS-PAGE and staining with a specific phosphoprotein stain (not shown). The ability of phosphorylated RGL2 to bind the activated form of H-Ras and Rap1b was compared to that of unphosphorylated RGL2 by using an ELISA format binding assay. As reported in Fig.7, phosphorylation of RGL2 by PKA significantly reduced the ability of RGL2(544-777) to complex both with H-Ras and Rap1b.

In this work we showed that the C-terminal end of RGL2-RBD, where the site of PKA phosphorylation is located, does not directly participate in the interaction, but may be crucial for the proper folding of the RBD domain. If a charged group is introduced in such a region, it can be expected that this event might strongly affect the conformation of the entire domain, thus resulting in a reduction of its ability to bind Rap and Ras.

To verify if phosphorylation of RGL2 by PKA occurs in intact mammalian cells as well, we overexpressed full length native and S737A RGL2 in HEK293 cells as fusions with GFP and then stimulated cells with forskolin as described in the Experimental Section. GFP-RGL2 or GFP- 
RGL2S737A were finally immunoprecipitated from cell protein extracts and analyzed by SDS-PAGE followed by ${ }^{\circledR}$ ProQ Diamond Staining to selectively stain phosphorylated proteins (Fig. 8A). Coomassie Brilliant Blue staining of the same gel (Fig.8B) and immunoblotting analysis of a control gel loaded with the same amount of samples (Fig.8C) were performed to evaluate relative amounts of GFP-RGL2 in the different lanes. Figure 8A shows that wild type RGL2 is phosphorylated in HEK293 cells (lane 2) and phosphorylation increases when cells are stimulated by forskolin (lane 1). The S737A mutant is phosphorylated as well, but there was no significant difference between stimulated and unstimulated cells in the level of phosphorylation (lanes 3 and 4). These data indicate that RGL2 is also phosphorylated by PKA in mammalian cells, and that Ser737 is the target of this phosphorylation; in addition, other residues of RGL2 may be phosphorylated by kinases other than PKA.

In summary, by combining mutagenesis analysis, in vivo and in vitro binding assays and homology modelling, we defined and characterized the minimal Ras/Rap binding domain of RGL2. This domain appears to be a fragment of 90 amino acids in the $C$-terminal part of the protein and includes the region of highest conservation between the RalGDS family members. The interaction with the effector domain of Ras and Rap is GTP-dependent and is mediated by a structural epitope conserved with Raf-1.

Our findings further indicate that RGL2, like the other RalGDS protein, has the potentiality to mediate the Ras-depending activation of Ral functioning as a downstream effector for Ras and an upstream activator of Ral. Thus, RalGDS proteins share important structural and functional features: they are ubiquitously expressed, they are able to act as effectors, although with different affinity, for Ras and Ras-related proteins, and they function as guanine nucleotide exchange factors for Ral. At present, it is not clear whether these proteins are functionally redundant or if they have distinct physiological roles, and how Ras proteins may distinguish these different interactors. Previous studies provided evidence supporting the hypothesis that Ras proteins may distinguish different effectors by their phosphorylation by PKA [37].

In this work we showed for the first time that only RGL2 is phosphorylated both in vitro and in mammalian cells by PKA at Ser737 and that phosphorylation significantly reduces the ability of RGL2 to bind H-Ras and Rap1b. RGL2 and Rlf are unique in the RalGDS family in that they have a PKA site in the RBD. Thus, while all RalGDS proteins are able to bind Ras proteins, in the case of RGL2/Rlf, this interaction may be regulated by PKA phosphorylation. These results suggest that Ras proteins may distinguish between the different RalGDS family members by their phosphorylation by PKA and support the hypothesis that this could be a general mechanism used by Ras to distinguish 
the different effectors. On the basis of our results in mammalian cells and structure analysis, we cannot exclude the possibility that other PKA-independent phosphorylation events may occur and may be involved in controlling other features of RGL2 signaling such as its intracellular localization or association with other proteins.

\section{AKNOWLEDGEMENTS}

This work was supported by grants from the Italian Ministry of University and Research (MIUR), COFIN, project n. 2002053415_003, 2002 and from the University of Siena (Piano di Ateneo per la Ricerca, Quota per Progetti, Esercizio 2005). We thank Linda van Aelst, Michel Wigler and Douglas Andres for reagents, M.Verani for skilful technical assistance and F.S.Retta for critical revision of the manuscript.

\section{REFERENCES}

1. Herrmann, C. (2003) Ras-effector interactions:after one decade. Curr. Opin. Struc. Biol. 13, 122-129.

2. Albright, C.F., Giddings, B.W., Liu, J., Vito, M., and Weinberg, R.A. (1993) Characterizaton of a guanine nucleotide dissociation stimulator for a ras-related GTPase, EMBO J. 12, 339-347.

3. Hofer, F., Fields, S., Schneider, C., and Martin, G.S. (1994) Activated Ras interacts with the Ral guanine nucleotide dissociation stimulator Proc.Natl.Acad.Sci.U.S.A. 91, 11089-11093.

4. Spaargaren, M., and Bischoff, J.R. (1994) Identification of the guanine nucleotide dissociation stimulator for Ral as a putative effector molecule of R-ras, H-ras, K-ras and Rap. Proc.Natl.Acad.Sci. U.S.A. 91, 12609-12613.

5. Kikuchi, A., Demo, S.D., Ye, Z.-H., Chen, Y.-W., and Williams, L.T. (1994) RalGDS family members interact with the effector loop of rasp21. Mol.Cell.Biol. 14, $7483-7491$.

6. Wolthuis, R.M.F., Bauer, B., van't Veer, L.J., de Vries-Smith, A.M.M., Cool, R.H., Spaargaren, M., Wittinghofer, A., Burgering, B.M.T., and Bos, J.L.(1996) RalGDSlike factor (Rlf) is a novel Ras and Rap1A-associating protein. Oncogene 13, 353362. 
7. Peterson, S.N., Trabalzini, L., Brtva, T.R., Fischer, T., Altschuler, D.L., Martelli,P., Lapetina, E.G., Der, C.J., and White, G.C. (1996) Identification of a novel RalGDSrelated protein as a candidate effector for Ras and Rap1. J.Biol. Chem. 271, 2990329908.

8. Shao, H., and Andres, D. (2000) A novel RalGEF-like protein, RGL3, as a candidate effector for rit and Ras, J.Biol.Chem. 275, 26914-26924.

9. Xu, J., Shi, S., Matsumoto, N., Noda, M., Kitayama, H. (2007) Identification of RGL3 as a potential binding partner for Rap-family small G-proteins and profilin II. Cell.Signal., 19, 1575-1582.

10. Quilliam, L.A., Rebhun, J.F., and Castro, A.F. (2002) A growing family of guanine nucleotide exchange factors is responsible for activation of Ras-family GTPases Prog.Nucleic.Acid Res.Mol.Biol. 71, 391-444.

11. Herrmann, C., Horn, G., Spaargaren, M., and Wittinghofer, A. (1996) Differential interaction of the ras family GTP-binding proteins H-Ras, Rap1A, and R-Ras with the putative effector molecules Raf kinase and Ral-guanine nucleotide exchange factor, J.Biol. Chem. 271, 6794-6800.

12. Koyama, S., Chen, Y.W., Ikeda, M., Muslin, A.J., Williams, L.T., and Kikuchi, A. (1996) Ras-interacting domain of RGL blocks Ras-dependent signal transduction in Xenopus oocytes, FEBS Lett. 380, 113-117.

13. O’Gara, M.J., Zhang, X., Baker, L., and Marshall, M.S. (1997) Characterization of the Ras binding domain of the RalGDS-related protein, Rlf, Biochem. Biophys. Res. Commun. 238, 425-429.

14. Geyer, M., Herrmann, C., Wohlgemuth, S., Wittinghofer, A., Kalbitzer, H.R. (1997) Structure of the Ras-binding domain of RalGEF and implications for Ras binding and signalling Nature Struct. Biol. 4, 694-699.

15. Kigawa, T., Endo, M., Ito, Y., Shirouzu, M., Kikuchi, A., and Yokoyama, S. (1998) Solution structure of the Ras-binding domain of RGL. FEBS Lett. 441, 413-418.

16. Esser, D., Bauer, B., Wolthuis, R.M., Cool, A., and Bayer, R.H. (1998) Structure determination of the Ras-binding domain of the Ral-specific guanine nucleotide exchange factor Rlf Biochemistry 371, 3453-13462.

17. Ponting, C.P., and Benjamin, D.R. (1996) A novel family of Ras-binding domains Trends Biochem. Sci. 21, 422-425. 
18. Huang, L., Weng, X., Hofer, F., Martin, G.S., and Kim, S.-H. (1997) Threedimensional structure of the Ras-interacting domain of RalGDS. Nat.Struct.Biol. 4, 609-614.

19. Broek, D., Toda, T., Michaeli, T., Levin, L., Birchmeier, C., Zoller, M., Powers, S., and Wigler, M. (1987) The S. cerevisiae CDC25 gene product regulates the RAS/adenylate cyclase pathway.Cell 48, 789-799.

20. Wolthuis, R.M., de Ruiter, N.D., Cool, R.H. and Bos, J.L. (1997) Stimulation of gene induction and cell growth by the Ras effector Rlf. EMBO J. 16, 6748-6761.

21. Herberg, J.A., Beck, S., and Trowsdale, J. (1998) TAPASIN, DAAX, RGL2, HKE2 and four new genes (BING 1, 3 to 5) form a dense cluster at the centromeric end of the MHC. J.Mol.Biol., 277, 839-857.

22. T Fischer, T.H., Brittain, J., Trabalzini, L., Banes, A.J., White, G.C., Smith, C.J., and Nichols, T.C. (2003) The ras-binding domain of ral GDS-like protein-2 as a ras inhibitor in smooth muscle cells, Biochem. Biophys. Res. Commun. 305, 934-940.

23. Pistolesi, S., Ferro, E., Santucci, A., Basosi, R., Trabalzini, L. and Pogni R. (2006) Molecular motion of spin labeled side chains in the C-terminal domain of RGL2 protein: a SDSL-EPR and MD study, Biophys. Chem. 123(1), 49-57.

24. Bradford, M.(1976) A rapid and sensitive method for the quantitation of microgram quantities of protein utilizing the principle of protein-dye binding, Anal.Biochem. 72, 248-254.

25. Ghosh, S., Xie, W.Q., Guest, A.F.G., Mabrouk, G.M., Strum, J.C., and Bell, R.M. (1994) The cysteine-rich region of Raf-1 kinase contains zinc, translocates to liposomes, and is adjacent to a segment that binds GTP-Ras, J.Biol.Chem. 269, 10000-10007.

26. Laemmli, U.K. (1970) Cleavage of structural proteins during the assembly of the head of bacteriophage T4, Nature 227, 680-685.

27. McCabe, P.C, Haubruck, H., Polakis, P., McCormick, F., and Innis, M.A. (1992) Functional interaction between $\mathrm{p} 21 \mathrm{rap} 1 \mathrm{~A}$ and components of the budding pathway in Saccharomyces cerevisiae. Mol.Cell.Biol., 12, 4084-4092.

28. Shirouzu, M., Hashimoto, K., Kikuchi, A., and Yokoyama, S. (1999) Double mutant analysis of the interaction of Ras with the Ras-binding domain of RGL, Biochemistry 38, 5103-5110. 
29. Wohlgemuth, S., Kiel, C., Kramer, A., Serrano, L., Wittinghofer, F., and Herrmann, C. (2005) Recognizing and defining true Ras binding domains I: biochemical analysis, J. Mol. Biol. 348, 741-758.

30. Block, C., Yanknecht, R., Hermann, C., Nassar, N., and Wittinghofer, A. (1996) Quantitative structure-activity analysis correlating Ras/Raf interaction in vitro to Raf activation in vivo. Nature Struct. Biol. 3, 244-251.

31. Shirouzu, M., Morinaka, K., Koyama, S., Hu, C.-D., Hori-Tamura, N., Okada, T., Fariya, K., Kataoka, T., Kikuchi, A., and Yokoyama, S. (1998) Interactions of the amino acid residue at position 31 of the c-Ha-Ras protein with Raf-1 and RalGDS, J.Biol.Chem. 273, 7737-7742.

32. Huang, L., Hofer, F., Martin, G.S., and Kim, S.-H. (1998) Structural basis for the interaction of Ras with RalGDS. Nat.Struct.Biol. 5, 422-426.

33. Avruch, J., Zhang, X.F., and Kyriakis, J.M., (1994) Raf meets Ras: completing the framework of a signal transduction pathway. Trends Biochem.Sci. 19, 279-283.

34. Daum, G., Eisenmann-Tappe, I., Fries, H.W., Troppmair, J., and Rapp, U.R., (1994) The ins and outs of Raf kinases. Trends Biochem. Sci. 19, 474-480.

35. Khosravi-Far, R., White, M.A., Westwick, J.K., Solski, P.A., ChrzanowskaWodnicka, M., Van Aelst, L., Wigler, M.H., Der, C.J. (1996) Oncogenic Ras activation of Raf/mitogen-activated protein kinase-independent pathways is sufficient to cause tumorigenic transformation. Mol.Cell.Biol. 16, 3923-3933.

36. Burridge, K., and Wennerberg, K. (2004) Rho and Rac take center stage. Cell 116, 167-179.

37. Kikuchi, A., and Williams, L.T. (1996) Regulation of interaction of rasp21 with RalGDS and Raf-1 by cyclic AMP-dependent protein kinase. J.Biol.Chem. 271, 588594.

38. Ikeda, M., Koyama, S., Okazaki, M., Dohi, K., and Kikuchi, A. (1995) Rap1 p21 regulates the interaction of ras $\mathrm{p} 21$ with RGL, a new effector protein of ras $\mathrm{p} 21$. FEBS Lett. 375, 37-40.

39. Sood, R., Malakowska, I., Carpten, J.D., Robbins, C.M., Stephan, D.A., Connors, T.D., Morgenbesser, S.D., Su, K., Pinkett, H.W., Graham, C.L., Quesenberry, M.I., Baxevanis, A.D., Klinger, K.W., Trent, J.M., and Bonner, T.I. (2000) The human RGL (RalGDS-like) gene: cloning, expression analysis and genomic organization. Biochim.Biophys.Acta, 1491, 285-288. 
B Biochemical Journal Immediate Publication. Published on 09 Jun 2008 as manuscript BJ20080255

40. Koradi, R., Billeter, M., and Wuthrich, K. (1996) MOLMOL: a program for display and analysis of macromolecular structures. J Mol Graphics, 14, 51-55. 


\section{FIGURE LEGENDS}

\section{Fig. 1: The RalGDS proteins sequence}

(A) Domain structure of RalGDS proteins. (B) Sequence alignment of the C-terminal region of RalGDS proteins containing the relative RBDs: RalGDS (rat, 767-867; mouse, 724-824 [2], human, 786-886 [4]), RGL (mouse, 634-736 [5]; human (634-736) [39], Rlf (635-737) [6], RGL2 (634-736) [7], and RGL3 (mouse, 596-697 [8]; human, 600-701 [9]). Sequence alignment was performed using the ClustalW program. Conserved residues are shaded in grey.

\section{Fig. 2: Deletion analysis of RGL2-RBD}

(A) Schematic representation of RGL2 deletion mutants used in this work. Black regions indicate conserved residues. (B) Results of the two-hybrid assay. cDNAs encoding the different fragments were fused in-frame with the GAL4 activation domain in pGAD424 vector. The different constructs were cotransformed into HF7c yeast strain together with pGBT9 vector containing wild type (WT) or mutated Rap1 and H-Ras. Protein-protein interaction was assayed by the ability of transformants to grow in minimal medium lacking His. His + transformants were assayed for $\beta$-galactosidase activity after 5 days of growth. ${ }^{a}$ Semiquantitative determination of $\beta$-galactosidase activity of the His + colonies. ++++ indicates blue staining detected within 1 hour, +++ indicates blue staining detected after 2 hours, ++ indicates blue staining detected after 3-4 hours, + indicates blue staining detected after 5-6 hours, and - indicates no blue staining after 8 hours. The results were obtained three times in independent experiments. (C) Binding of different GST-RGL2 fusion proteins to HRas in the ELISA format assay. The procedure is detailed in the Experimental section. $\mathrm{Gpp}(\mathrm{NH}) \mathrm{p}$ was added to the incubation buffers used in the assay to a final concentration of $50 \mu \mathrm{M}$ to prevent significant hydrolysis of GTP during the time course of the assay. Binding curves were generated by serially varying the concentration of the different RGL2 fragments while maintaining the Ras amount at $50 \mathrm{pmol} / \mathrm{well}$. Recombinant GST was used as test protein in a negative control assay and determined the background binding of the assay. Protein-protein interaction was detected by using anti-GST antibody (1:3000 dilution) and anti-goat IgG-peroxidase conjugate antibody (1:25000 dilution). Absorbance values are plotted as a function of the test protein concentration. GST-RGL2(647-736), _ـ GSTRGL2(677-736), …........ ; GST-RGL2(647-706), - - $\mathbf{A}$ - - ; GST, - · - - · .

The data shown are representative of three separate assays performed in triplicate. 


\section{Fig. 3: RGL2-RBD structure and Ras binding}

(A) RGL2-RBD three-dimensional structure. Ribbon diagram of the tertiary fold of RGL2 (647-736) where the five $\beta$-strands are in pink and the two $\alpha$-helices are in yellow [23]. The side chains of the residues mutated in this work are shown in ball-and-stick. The different colors indicate the different effects of substitution with Ala in the interaction with Ras/Rap: green, abrogation; orange, decreasing; grey, increasing; blue: no effect.

(B) Three-dimensional structure of the RGL2-RBD/Ras complex. To build the RGL2$\mathrm{RBD} /$ Ras complex model, the crystallographical structure of the RalGDS-RBD/Ras complex (pdb ID 1LFD) was used as reference. The RGL2-RBD structure was fitted on the RalGDS structure using all the mainchain atoms. Fitting procedures and picture preparation were done using MolMol software [40].

Ras protein (grey), RGL2 residues involved in the interaction (green) and Arg682 (blue) are represented in CPK.

Fig. 4: In vitro guanine nucleotide exchange factor activity of RGL2 for different small GTPases

A. GEF activity of RGL2(1-518) for H-Ras, RalA, Rap1b, Rac1 and RhoA.

H-Ras, - O- -; H-Ras + RGL2(1-518), - O- -; RalA, $-\triangle \longrightarrow$;

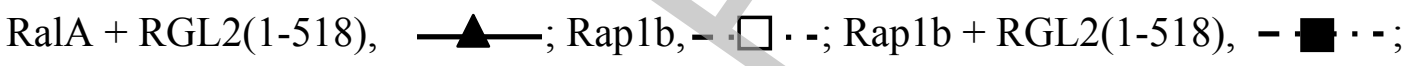

Rac1, $\cdots \diamond \cdots \cdots \cdot \operatorname{Rac} 1+\operatorname{RGL} 2(1-518), \cdots \diamond \cdots \cdot$; RhoA, 一 X - ;

RhoA + RGL2(1-518), - - -

B. GEF activity of RGL2(83-518) for RalA.

RalA, - $\square \cdot-$; RalA + RGL2(83-518), - - · ·

The guanine nucleotide exchange assay was performed as described in the Experimental section. Values are expressed as the percentage of the zero time point which was arbitrarily set at 100 . Each value is the average of triplicate incubations and is representative of three separate experiments.

\section{Fig. 5 : Sequence alignment of RGL2 and CDC25}

The N-terminal 518 aminoacids of RGL2 and CDC25 were aligned using the ClustalW program. Conserved residues are shaded with black. The core catalytic domain of CDC25 is underlined with a continuous line; the REM domain is underlined with a dotted line. 
Fig. 6: In vitro phosphorylation of RGL2-RBD

After phosphorylation by PKA, GST-fused RGL2 mutants and GST were analyzed by SDSPAGE on $12.5 \%$ (A) or $12 \%$ (B) gels followed by autoradiography. (A) Lane \#1- GSTRGL2(262-777); Lane \#2- GST-RGL2(681-777); Lane \#3- GST negative contro1. (B) Lane \#1- GST-RGL2(544-777)S737A; Lane\#2- GST-RGL2(544-777). Molecular mass is indicated in $\mathrm{kDa}$ on the left of the figure.

Fig. 7: Effect of the phosphorylation of RGL2 on its binding to H-Ras and Rap1b

The unphosphorylated (GST-RGL2(544-777)) or phosphorylated (pGST-RGL2(544-777)) form of RGL2 and GST were used as test proteins in an ELISA format in vitro binding assay to evaluate their interaction with $\mathrm{H}-\mathrm{Ras}(\mathrm{G} 12 \mathrm{~V})$ and $\operatorname{Rap} 1 \mathrm{~b}(\mathrm{G} 12 \mathrm{~V})$.

Rap1b/GST-RGL2, - ; Rap1b/pGST-RGL2, 一- ;

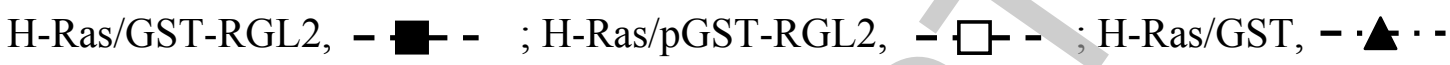

The procedure of this experiment is detailed in the Experimental section and in Figure 1C. The results shown are representative of three independent experiments performed in triplicate.

Fig. 8: Phosphorylation of RGL2 in HEK293 cells

Cells were transfected with pEGFP-RGL2 or pEGFP-RGL2S737A and treated with forskolin as described in the Experimental section. GFP fusions of wild-type RGL2 and the S737A mutant were immunoprecipitated from cell lysates and then analyzed by SDS-PAGE followed by phosphoprotein specific ProQ staining (A), Coomassie Brilliant Blue Staining (B), or immunoblotting analysis with anti-GFP antibody (C).

UT: untrasfected cells. 


\section{TABLES}

\section{Table 1}

\section{Mutation analysis of the interaction of RGL2-RBD and Rap/Ras}

Wild type Rap1b and H-Ras fused in pGBT9 were used to cotransform HF7c yeast strain along with different mutants of RGL2(647-736), prepared as described in the Experimental section. $\beta$-galactosidase activity of the His + colonies was evaluated as reported in the legend to Fig.2B.

\begin{tabular}{lcc}
\hline & \multicolumn{2}{c}{$\boldsymbol{\beta}$-galactosidase activity } \\
H-Ras & Rap1b \\
\hline Wild Type & +++ & ++ \\
R653A & - & - \\
Y665A & + & + \\
K666A & - & - \\
R682A & +++ & +++ \\
K686A & - & - \\
N687A & + & + \\
D690A & ++++ & ++ \\
Y719A & ++ & + \\
\hline
\end{tabular}




\section{Table 2}

\section{Double mutant analysis of the interaction of RGL2-RBD and Rap/Ras}

Wild type Rap1b and H-Ras and their mutants on the effector domain fused in pGBT9 were cotransformed into HF7c together with wild type and two mutants of RGL2-RBD. $\beta$ galactosidase activity of the His + colonies was evaluated as reported in the legend to Fig. $2 \mathrm{~B}$.

\begin{tabular}{lccc}
\hline & \multicolumn{3}{c}{$\boldsymbol{\beta}$-galactosidase activity } \\
& WT & K686A & D690A \\
\hline H-Ras(WT) & +++ & - & ++++ \\
H-Ras(T35A) & - & - & - \\
Rap1b(WT) & ++ & - & ++ \\
Rap1b(T35A) & - & - & - \\
Rap1b(E37G) & + & - & +++ \\
\hline
\end{tabular}




\section{FIGURES}

A.

$\mathrm{NH}_{2}-$\begin{tabular}{|l|l|l|l|l|l}
\hline & REM & CDC25 & & RBD & $-\mathrm{COOH}$ \\
\hline
\end{tabular}

B.

RalGDs rat

RalGDs mouse RalGDs human RGL mouse RGL human Rlf mouse RGL2 human RGL 3 mouse RGL3 human

RalGDs rat RalGDS mouse RalcDs human RGL mouse RGL human Rlf mouse RGL2 human RGL 3 mouse RGL 3 human
767 SSS-L-PLYMQQVGDCCI IRVSL-D-VDNGUUŸKSILVISQDKAPTVIRKAND

724 SSS-L-PLYNQQVGDCCI IRVSL-D-VDNCUMYKS I LVTSQDKAPTV IRKAND

790 SSA-L-PL YNQQVGDCCI IRVSL-D-VDNGUMYKSILVTSQDKAPAVIRKAND

634 TSTVLP PVYNQQVEDTCI IRISVEDN--NGMUYSIMLTSQDKTPAVIQRANS

634 TSTVLPPVYNQQNEDTCI IRISVEDN-=NGMMYKSTMLTSQDKTPAVIQRANL

635 SAGCGGGVSGPGSSDCRI IRVQMELGED-GSVYKSILVTSQDKAPSVISRVLK

634 GTGYGGEGSGPGASDCRI IRVQMELGED-CSVYKSILVTSQDKAPSVISRVLK

596 SSSRV-PLLGQQTSEARVIRVSIN-NNH-GNLYRSILLTCQDKAPSVVQRALE 600 GSPRI-PLPAQQSSEARVIRVSID-NDH-GNLYRSILLTSQDKAPSVVRRALQ

818 NLDEDEPEDYELLQIISEDHKL I PENANVFYAMNS---AANYDFILKKRAFT 775 NLDEDEPEDYELVQIISEDHKLKI PENANVFY AMNS-=-TAKYDF ILKKRTFT 837 NLEEEEPEDY ELLOILSDDRKLKI EENANVFYAMNS-=-TANYDFVLKKRTFT 687 NLESDPREEYELVQVISEDKELVIPDSANVFY AMNS-=-QVHFDFILRKKNSV 687 NLDSDPREEYEL VQVISEDKELVI PDSANVFY AMNS-=-QVHFDF IL RKKKSM 689 NRDSAVASEFEL VQLLPGDRELTI PHSANVFY $A M D G=-m A S H D F L L R Q R R R$ 688 NRDSAVASEYELVOLLPGERELTIPASAMVFYAMDG-=--nSHDFLLRQRRRS 650 NVPQPWAR DYQLFQVLPGDRELLI PDGAWVFY MSP - -AAPGDFLLRRKEGT 652 NVPQPWRCDYQL FQVLPGDRVLLI PDNANVFYAMSP-=-VAPRDFML RRKEGT

\section{Figure 1}

Licenced copy. Copying is not permitted, except with prior permission and as allowed by law.

(C) 2008 The Authors Journal compilation (C) 2008 Biochemical Society 
Biochemical Journal Immediate Publication. Published on 09 Jun 2008 as manuscript BJ20080255

A.
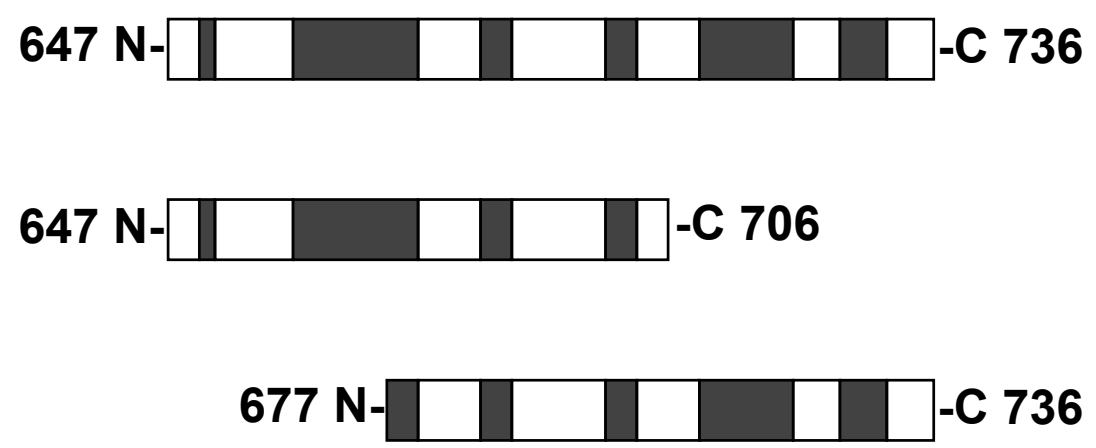

B.

\begin{tabular}{llll}
\hline & \multicolumn{3}{c}{$\beta$-galactosidase activity } \\
RGL2 mutants & $(647-736)$ & $(647-706)$ & $(677-736)$
\end{tabular}

\begin{tabular}{lccc}
\hline HRas(WT) & +++ & - & - \\
HRas(G12V) & +++ & - & - \\
HRas(S17N) & - & - & - \\
Raplb(WT) & ++ & - & - \\
Rap1b(G12V) & ++ & - & - \\
Raplb(S17N) & - & - & - \\
\hline
\end{tabular}

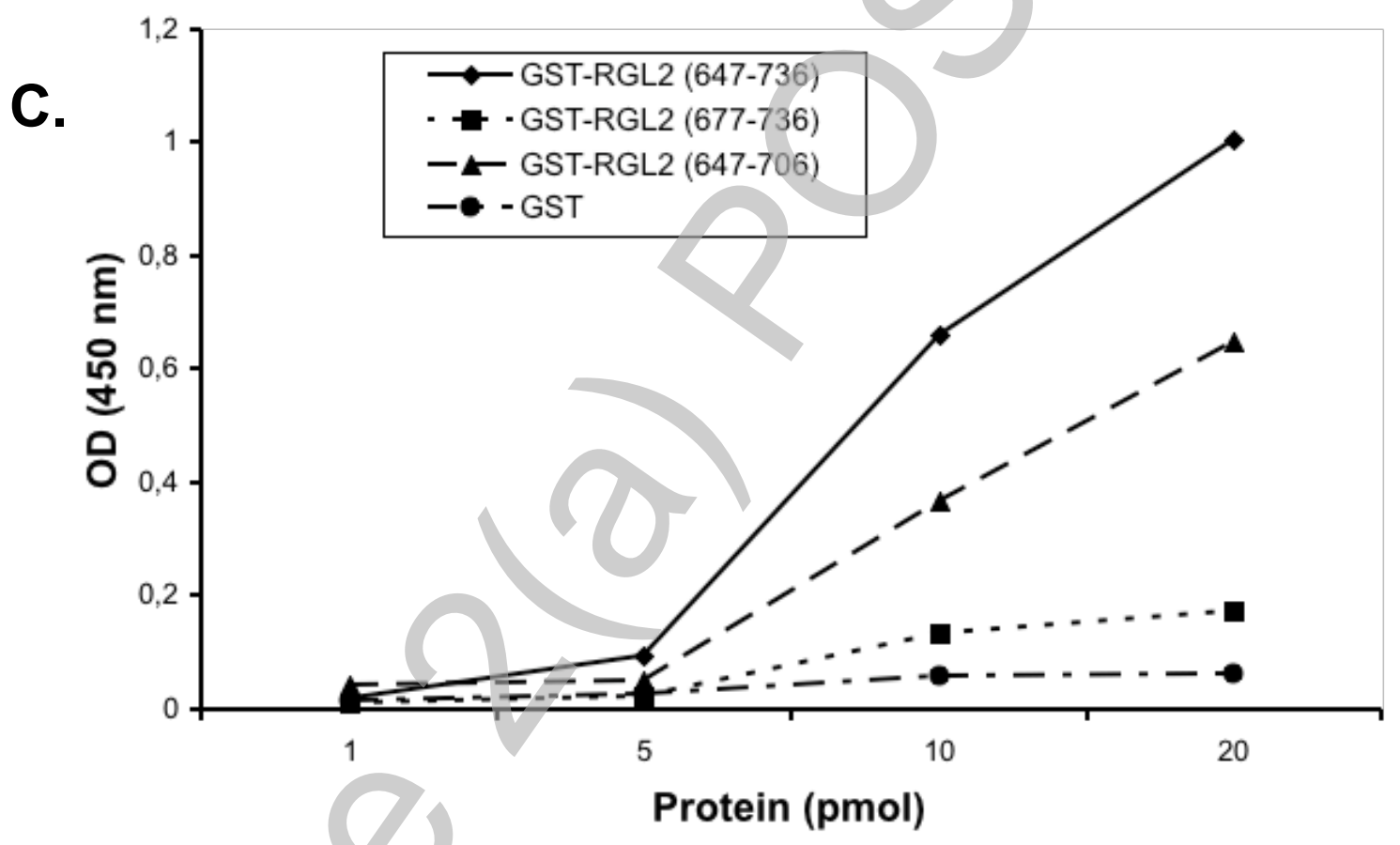

Figure 2 


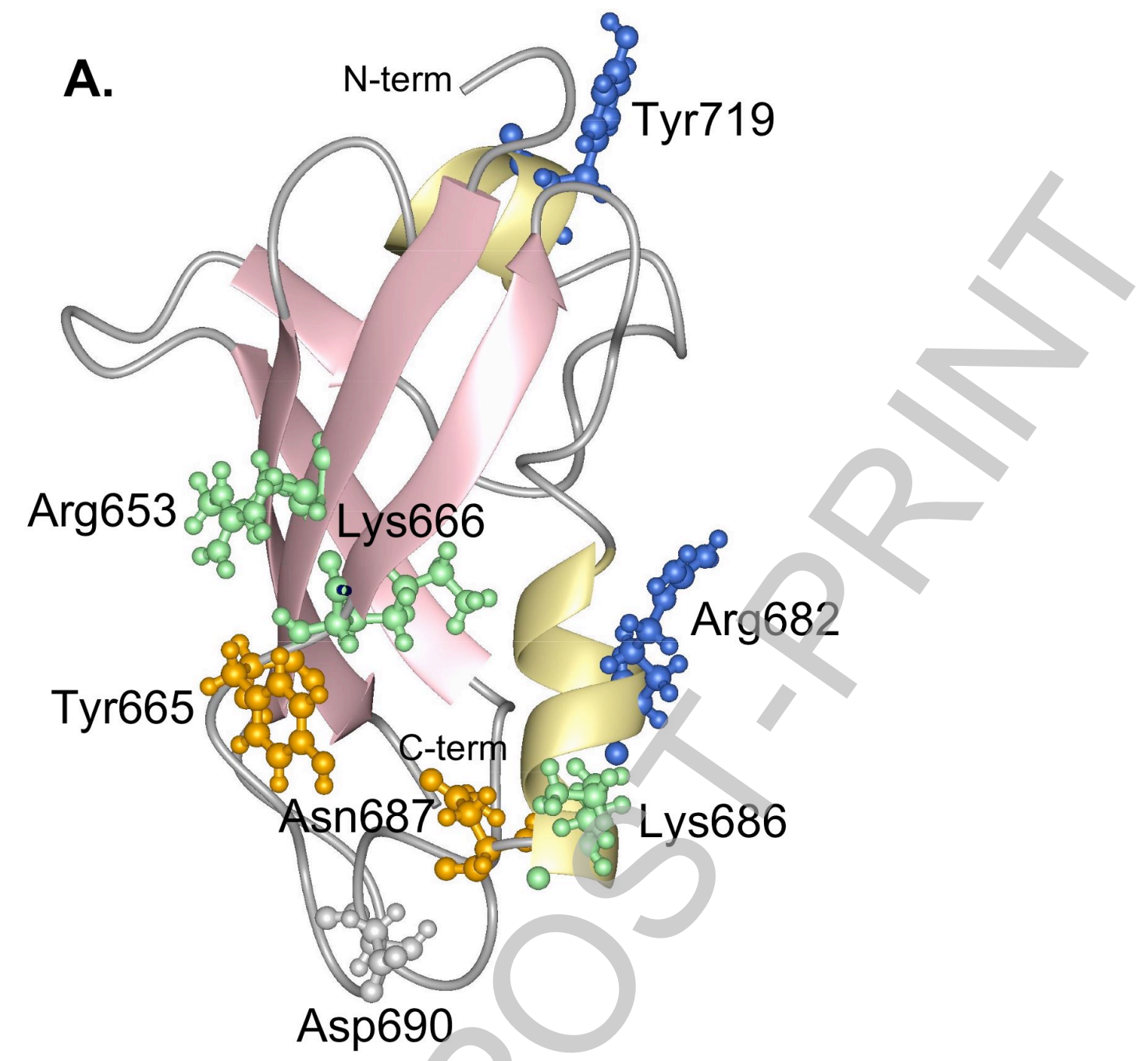

B.

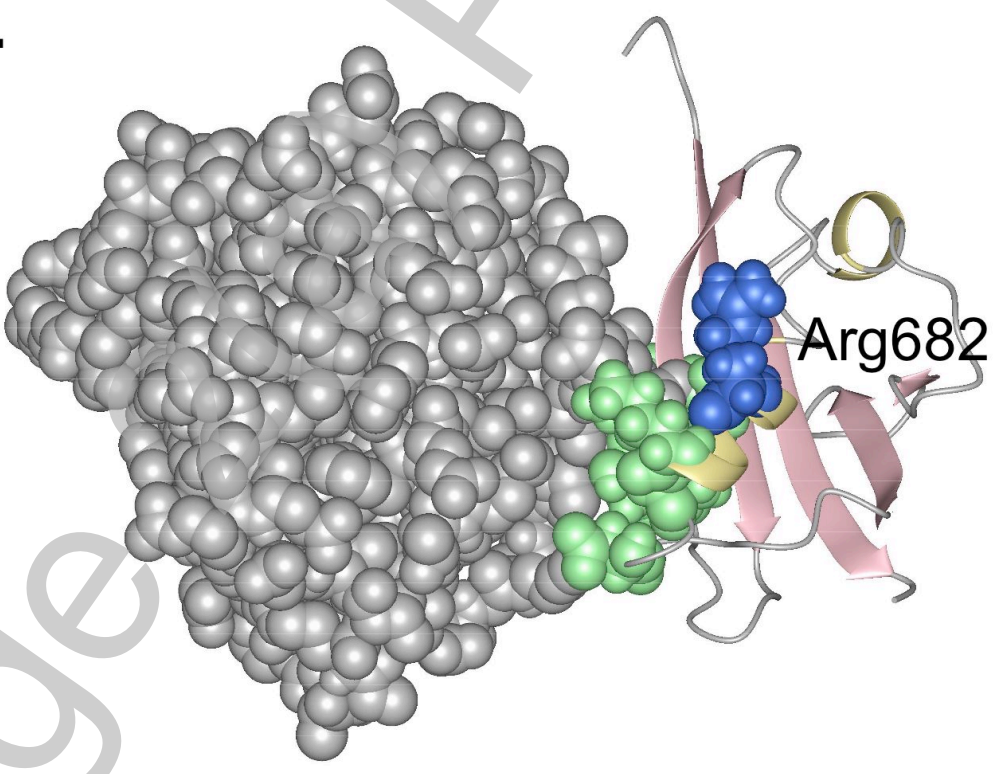

Figure 3 

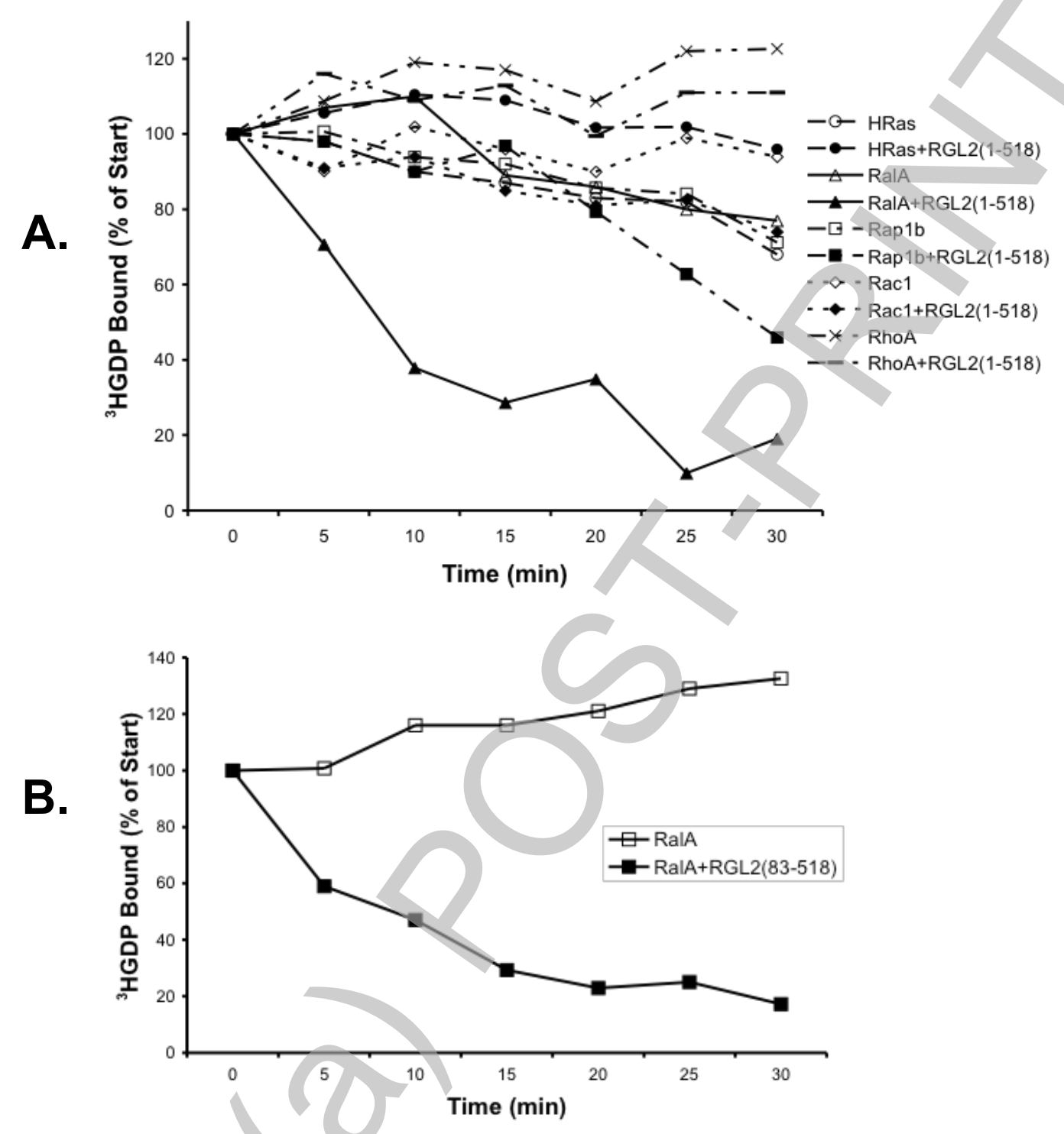

Figure 4

Licenced copy. Copying is not permitted, except with prior permission and as allowed by law. (C) 2008 The Authors Journal compilation (C) 2008 Biochemical Society 
Biochemical Journal Immediate Publication. Published on 09 Jun 2008 as manuscript BJ20080255

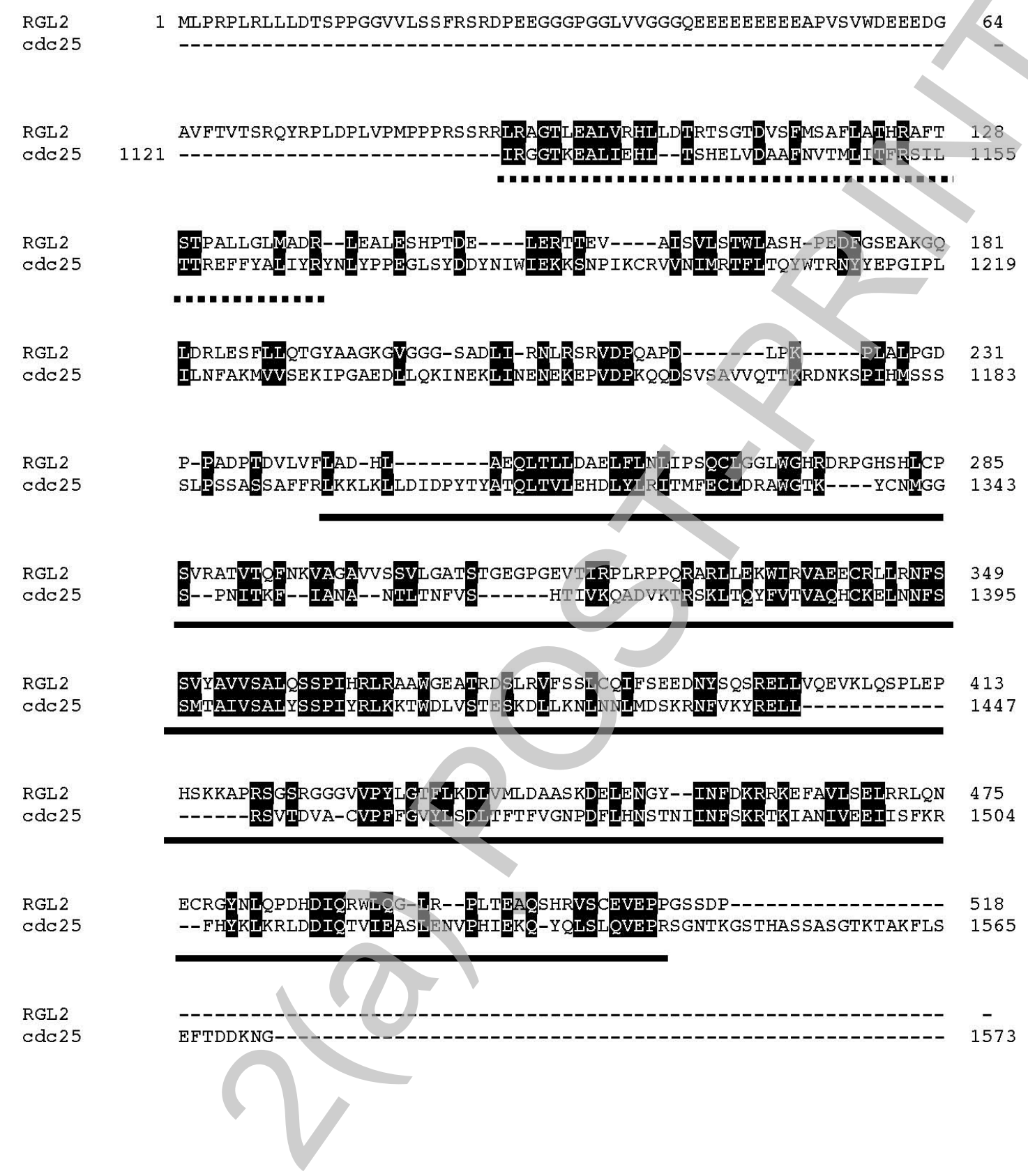

Figure 5

Licenced copy. Copying is not permitted, except with prior permission and as allowed by law.

(C) 2008 The Authors Journal compilation (C) 2008 Biochemical Society 
A.

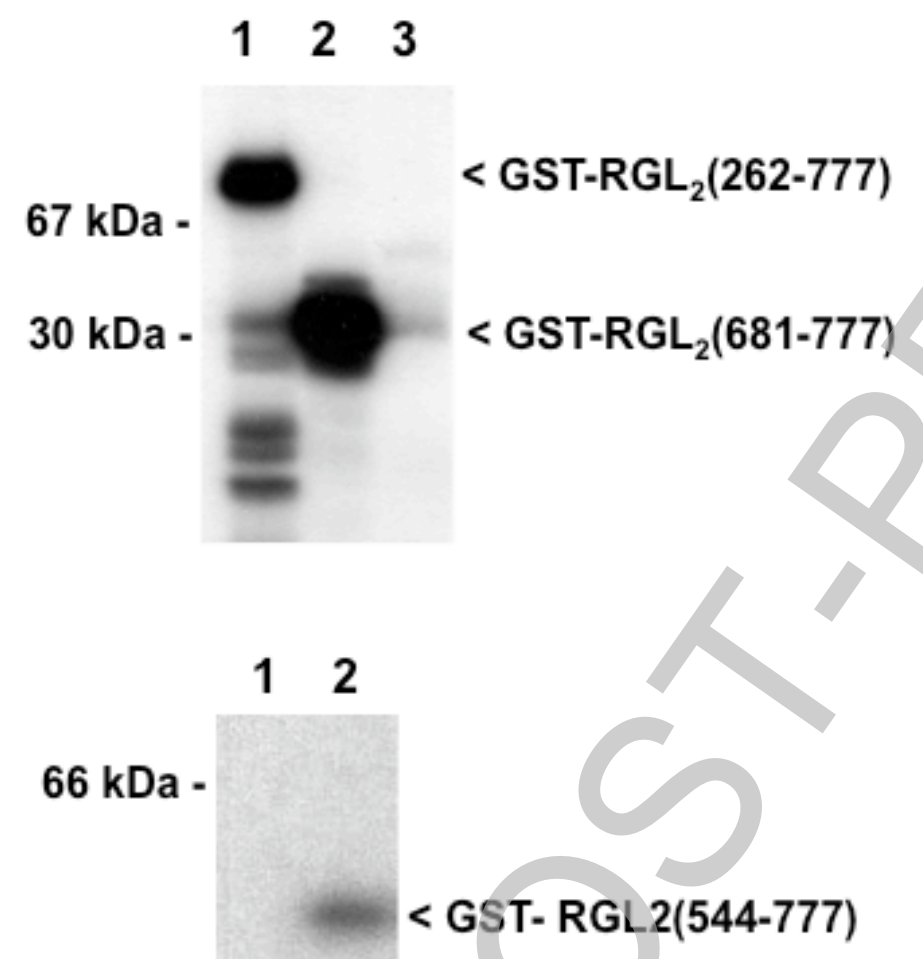

Figure 6

$45 \mathrm{kDa}$ - 


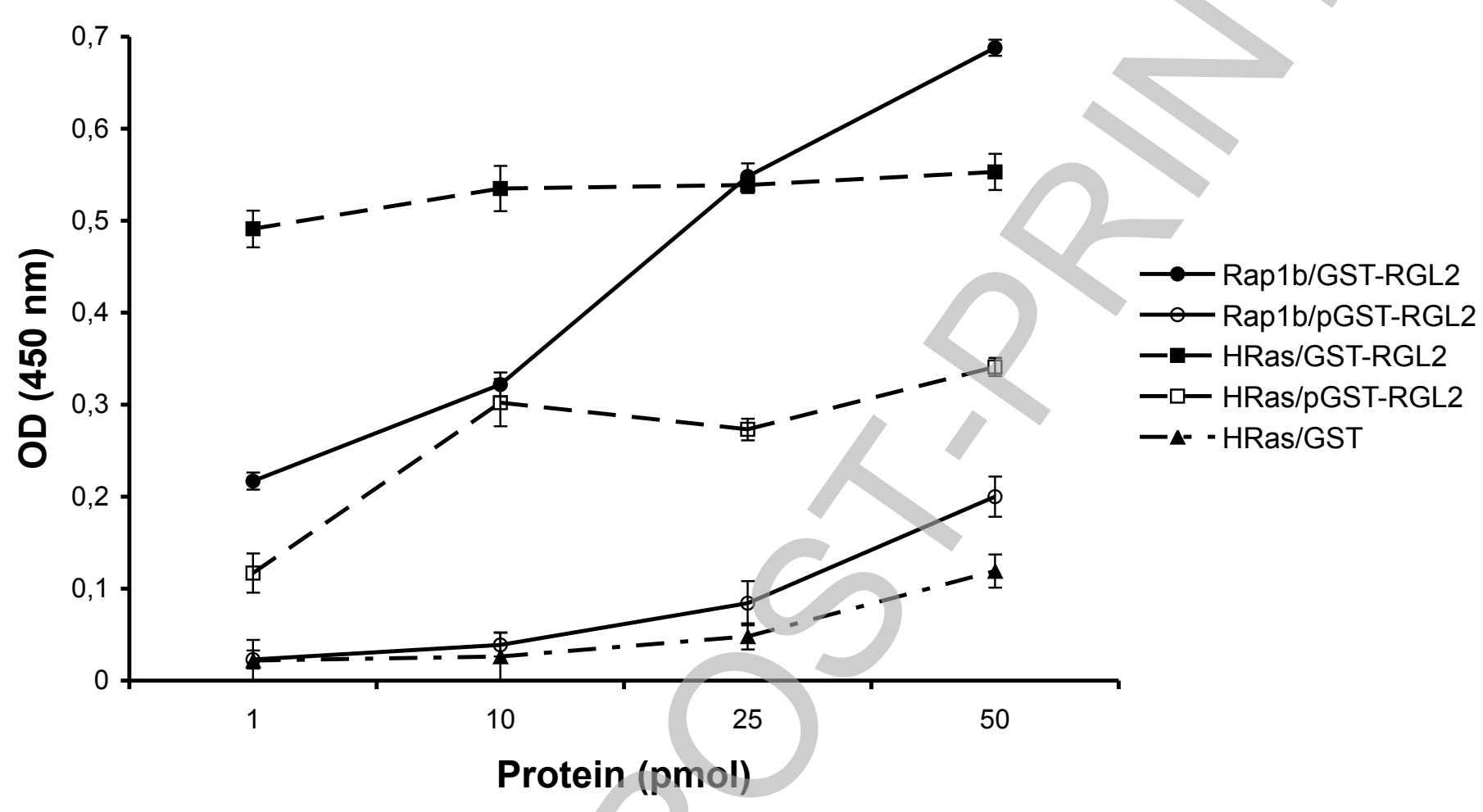

Figure 7 


\section{Figure 8}

A.

B.

\section{GFP-RGL2}
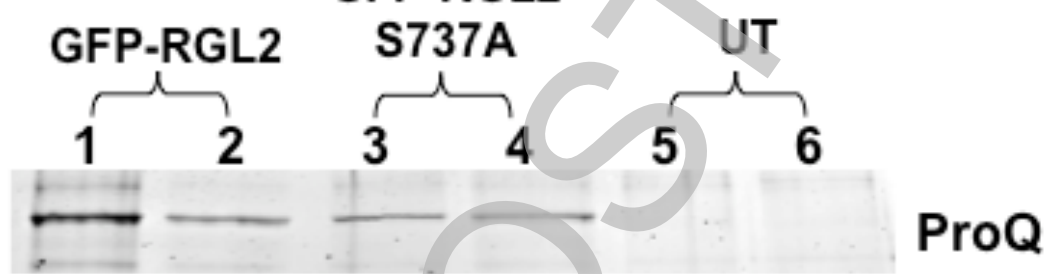

C.

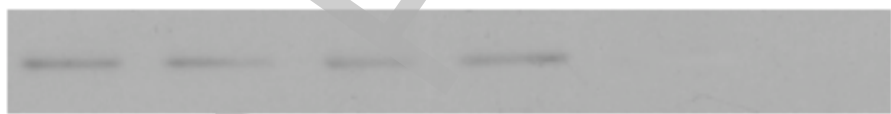

Coomassie anti GFP

Forskolin + 